\title{
Cisplatin-E Therapeutic Implant
}

National Cancer Institute

\section{Source}

National Cancer Institute. Cisplatin-E Therapeutic Implant. NCI Thesaurus. Code C17879.

An injectable gel comprised of a collagen matrix containing the inorganic platinum (Pt) agent cisplatin and the sympathomimetic agent epinephrine with potential antineoplastic activity. After intratumoral injection, cisplatin forms highly reactive, positively charged, platinum complexes, which covalently bind to nucleophilic groups in DNA, preferably at the N7 position of guanine bases. This induces both intra- and inter-strand DNA crosslinks. In addition, cisplatin forms DNA-Pt-protein cross-links. Cross-link formation results in both the induction of apoptosis and cell growth inhibition. Epinephrine, a potent vasoconstrictor, is added to the gel to both enhance the penetration of cisplatin into tumor tissue and reduce its dispersion into the surrounding tissues. Intratumoral injection of cisplatin-E therapeutic implant may increase local chemotherapeutic efficacy, as compared to the systemic administration of cisplatin, while reducing its systemic toxicity. 